This PDF is a selection from an out-of-print volume from the National Bureau of Economic Research

Volume Title: Aging Issues in the United States and Japan

Volume Author/Editor: Seiritsu Ogura, Toshiaki Tachibanaki and David A. Wise, editors

Volume Publisher: University of Chicago Press

Volume ISBN: 0-226-62081-6

Volume URL: http://www.nber.org/books/ogur01-1

Publication Date: January 2001

Chapter Title: Promotion, Incentives, and Wages

Chapter Author: Toshiaki Tachibanaki, Tetsuya Maruyama

Chapter URL: http://www.nber.org/chapters/c10294

Chapter pages in book: (p. 335 - 360) 


\title{
Promotion, Incentives, and Wages
}

\author{
Toshiaki Tachibanaki and Tetsuya Maruyama
}

\subsection{Introduction}

In many advanced countries, there is a growing interest in the relationship between incentive pay and careers in organizations, and in particular between incentive pay and promotion on the hierarchical ladder. There are two main reasons for this: First, theoretical economists in general are interested in firms, contracts, incentives, performance, and the like. Second, a number of surveys on wages, positions, performance, and other features of individual employees have become available recently. These surveys enable economists to conduct rigorous empirical studies more efficiently than aggregate data did.

This paper investigates the story of Japanese firm experience with incentive pay. Since both the aging of the Japanese population and the slower growth rate of Japanese firms force those firms to reduce the cost of labor (by decreasing the total wage cost), the system must not reduce the work incentives of employees who may see a decrease in their average wages.

In Japan it has been understood that the average labor productivity of manual (blue-collar) workers is quite high, while that of nonmanual (whitecollar) workers is considerably lower than it is in other industrialized nations. There are several convincing reasons for this belief. First, team production is common among manual workers in manufacturing, and such a system is apt to increase labor productivity because neither strong leadership nor excellent contribution by a single person is required. In other words, among manual workers everyone is motivated to raise the average productivity. Second, nonmanufacturing industries in which the majority

Toshiaki Tachibanaki is professor of economics at Kyoto University. Tetsuya Maruyama is a graduate student of economics at the University of Pennsylvania. 
of workers are white-collar exhibit lower labor productivity; that implies that the average labor productivity of white-collar workers is lower than that of blue-collar workers. Third, leadership, individual contributions, and the workers' skills are all crucial in determining productivity of whitecollar workers who are engaged in complicated jobs. Fourth, compressed wage dispersion among workers and a seniority-based promotion system, two representative features of the industrial relations system in Japan, are relevant for manual workers, but not suitable for white-collar workers. ${ }^{1}$ This study examines whether that latter statement is true for white-collar workers.

\subsection{Theoretical and Empirical Facts on Incentives and Careers}

Two important articles focusing on the United States deal with the relationship between incentive pay and careers in organizations (Gibbons 1997; Prendergast 1999). This section therefore relates strictly to the experience of Japan. In particular, we ask, "Does pay vary with performance, and do incentives matter, particularly for white-collar workers?"

Two important earlier studies investigated the issues of insurance, contracts, and incentives in Japan: Mitani (1998) and Ito and Teruyuma (1998). It is useful to summarize their findings here. Mitani investigated the positive and the negative effects of the incentive for wages and promotion on employees in terms of individual and firm performance. Workers who are fond of risk-taking, and who clearly understand the relationship between incentive and performance, are affected positively; workers who are risk averse and who do not appreciate the effect of incentives on their performance are affected negatively. Mitani found that the Japanese incentive system was at an optimal level, balancing the positive and the negative effects perfectly.

Ito and Teruyama (1998) were concerned with the economic effect of job tenure on wages and promotion. They found that no single theory could explain this relationship perfectly. These two studies were important, however, because they were the first attempts (at least for Japan) to depart from human capital as the sole background theory for explaining wage differentials. ${ }^{2}$

Job tenure in Japan has a particularly strong effect on the determination of wages and promotion. Wages increase almost proportionately with job tenure in the firm and decrease after a certain point. ${ }^{3}$ The influence of job tenure also has been examined in the determination of promotion along

1. See Lazear (1989) about the implication of compressed wage dispersion.

2. The theory of human capital had been dominant in Japan for a long time, although some dissatisfaction with it has been addressed (e.g., Ishikawa 1992; Tachibanaki 1996).

3. Many empirical studies have attempted to determine the role of tenure in the determination of wages. See, for example, Mincer and Higuchi (1988) and Tachibanaki (1996). 
the hierarchical ladder in organizations. This effect of job tenure on wages and promotion is called the seniority rule in Japan, and is one of the most important institutional features in industrial relations.

Currently there is a shift of interest in the role of job tenure from wages to promotion. There are two conflicting views on the questions "Who is promoted?" and "What are the main criteria for the determination of promotion?" The first view gives the role of job tenure (seniority) and the performance of the individual employee almost equal significance. ${ }^{4}$ The second view emphasizes the performance of the individual employee over seniority. $^{5}$

Of course, promotion rates differ by industry and depend on the growth rate of the firm. Tomita (1992) looks at bank, while Ohtake (1995) and Ariga and his coauthors (1997) study electric firms which have considerably higher growth rates in their sales and their employment. ${ }^{6}$ Promotion policies also differ among the particular firms, even in the same industry and with similar growth rates. Matsushige (1998) shows that seniority plays a very important role for those with ten to thirteen years of job tenure, even in one very large electric company with a growth rate that is only moderate. In that firm, no one is promoted before accumulating those ten to thirteen years of tenure.

Our data cover various industries. Thus, we can avoid the effect of a specific industry's experience on the results. Also, the data include different rates of firm growth, although we consider only larger firms.

One interesting question is the role of education in promotion rates. It may be a signaling effect, in the sense that only university graduates will be promoted and non-university graduates will have a very slim chance of promotion. This is particularly true in larger firms (see, e.g., Tachibanaki 1996). There is also the issue of "what university he or she graduated from." Academic credentials, that is, the name of the university, matter to a considerable extent in the determination of promotion. ${ }^{7}$ In sum, education plays a special role in promotions, particularly in Japan.

Some natural questions arise after these issues are examined. First, what is the effect of position or promotion on wage increases? How are wages distributed among workers who are promoted to higher positions versus those who are not? Second, do early promotions or quick wage increases better induce higher motivation and work incentives, and thus raise individual productivity? Which is more influential in determining workers' in-

4. Tomita (1992) is a typical example of this view.

5. See Ohtake (1995), Ariga, Ohkusa, and Brunello (1997), Bruderl, Diekman, and Preisendörfer (1991), and Baker, Gibbs, and Holmstrom (1994a,b) for the United States; they find a "fast track" or "serial correlation" in promotion rates.

6. See also Ohashi and Matsushige (1994) for the effect of firm growth rate on promotion.

7. See, for example, Tachibanaki (1998a) and Ohashi (1998). This also can be interpreted in the framework of favoritism, as in Prendergast and Topel (1996). 
centives, position or remuneration? Third, how do different positions on the hierarchical ladder affect incentives?

\subsection{Model Specification}

This section presents three basic models that describe the relationship of promotions and wages. The three models are presented in the appendix.

Model I shows the relationship between promotion and incentive. In particular, it gets at whether a promotion raises a worker's incentive, expressed as EFFORT. Put more simply, does an employee who has been successful in his career (promoted to a higher position) work hard and efficiently, or simply respond to higher incentives? Of course, there is the possibility of the inverse causality, in which a highly motivated and hardworking employee is more likely to be promoted. Both questions are posed in Model I.

Model II considers a similar problem. The crucial difference, however, is that it investigates the relationship between incentives and wages rather than between promotion and incentives. The difference between promotion and wages in terms of their effect on effort (incentives) can be estimated by comparing the empirical results of Model I and Model II.

It is likely that these three variables-promotion, incentive, and wages - are jointly determined. In other words, they may be endogenous. Therefore, Model III is a simultaneous equation model. Both Model I and Model II are also simultaneous equations models, despite the fact that they have only two endogenous variables, respectively.

One important feature of this study is the discrete nature of several of the endogenous variables. Typically, promotion is defined by zero (not promoted) or one (promoted). This discrete nature must be considered with a simultaneous equation framework.

Finally, we adopt a large number of exogenous (independent) variables in estimating these models. These include not only demographic variables for each employee, such as education, job tenure, and the like, but also several subjective evaluations and preferences for promotion and the incentives of each employee. These subjective variables are expected to answer the following questions: "What variables are influential?" and, "What variables are not important in the determination of the relationship among promotion, incentive, and wages?"

\subsection{Data and Institutional Features}

The data used in this study come from a survey conducted in 1993 of white-collar employees in five large firms: an automobile manufacturer, an electronics manufacturing company, a chemical firm, an electric power company, and a department store. The sample includes not only manage- 
rial and administrative employees (who were promoted) but also employees who were not promoted. In total, 2,100 questionnaires were sent to employees, and there were 1,816 responses. The high response rate, 86.5 percent, was achieved because both the firms and the labor unions helped us greatly.

It is useful to describe several institutional features that govern the promotional system in large firms in Japan in order to understand the empirical results. First, seniority (job tenure) has been quite important in determining the promotions to certain positions, and is still important in some industries. ${ }^{8}$

Second, strict promotion proceeds vertically, from ordinary worker (not promoted), to section head (kakari-cho), to department head (kacho), to director (bucho), and finally to executive (torishimariyaku). In many cases, deputy positions serve as preparation for department heads and directors. A section is the smallest employee unit, consisting of roughly two to five members. A department is the intermediate unit, consisting of roughly five to thirty members. A directorate is the largest unit, consisting of roughly twenty to one hundred or even more members. The number of members in each section, department, and directorate differs considerably from firm to firm.

Third, several types of department heads have no subordinates. In other words, they have only the titles without any supervisory tasks. Nevertheless, they are treated almost exactly like department heads with regard to qualifications and grades, which determine wage payments. In many cases, they work as specialists rather than managers.

Why would firms establish department heads who do not have any subordinates? First, the aging trend in the population plus the slower growth rate of firms has reduced the available number of department head positions. In other words, firms are unable to promote a large number of employees to department heads unless there are changes in firms' hierarchical structures. Second, employees who have not been promoted to department heads for those reasons may lose their incentive to work because of their lower wages and a lower degree of responsibility. Third, the seniority system, which guarantees promotion of all employees to department head, may ensure a good working environment within the firm. Finally, there are several important and specialized jobs that can be done without subordinates, and there is an increasing trend toward these jobs in many firms. These four conditions have encouraged firms to create the position of department head with no subordinates. Employees are entitled to be called department heads, and they receive nearly the same amount of wages as those department heads who do have subordinates.

8. See for example, Tachibanaki (1982) for earlier studies that showed the importance of seniority. 


\subsection{Empirical Results}

Tables 11.1 through 11.12 present the estimated results for the three models. Many of the tables include two or three estimated results separated from those for the full samples. These estimates are according to position in the hierarchical ladder of a firm, and are done for all employees, employees who are section heads or higher (thus being promoted to department head), and employees who are department heads or higher (being promoted to director or deputy director). These distinctions are quite important, because the positions are crucial in determining promotion possibility, incentives, and wages. When there are several endogenous variables in the model, the two-stage least squares (2SLS) method is applied. When one of the dependent variables is defined discretely, special methods, such as the two-step Heckman method, are undertaken in addition to the 2SLS.

Table 11.1 shows the estimated effort function calculated by the ordi-

Model I, Estimated Effort Function (OLS)

\begin{tabular}{lcc}
\hline & Coefficient (A) & Coefficient (B) \\
\hline Constant & $2.729^{* *}$ & $2.911^{* *}$ \\
& $(0.144)$ & $(0.262)$ \\
STD & $0.157^{*}$ & 0.086 \\
& $(0.085)$ & $(0.133)$ \\
SAWD & $-0.569^{* *}$ & $-0.632^{* *}$ \\
WVARD & $(0.083)$ & $(0.135)$ \\
& -0.208 & -0.111 \\
OPD & $(0.128)$ & $(0.199)$ \\
& -0.208 & 0.218 \\
AGRD & $(0.128)$ & $(0.139)$ \\
& $0.148^{*}$ & 0.048 \\
PROSD & $(0.084)$ & $(0.217)$ \\
& 0.001 & $0.264^{* *}$ \\
PNOTICED & $(0.122)$ & $(0.142)$ \\
& -0.007 & -0.005 \\
PVARD & $(0.098)$ & $(0.173)$ \\
& 0.016 & -0.105 \\
PROM & $(0.100)$ & $(0.198)$ \\
& 0.063 & -0.175 \\
$\bar{R}^{2}$ & $(0.084)$ & $(0.164)$ \\
& 0.177 & 0.157 \\
\hline
\end{tabular}

Source: Data are from Tachibanaki and Maruyama (1993).

Notes: See appendix for an explanation of variables. Figures in parentheses are standard errors. For sample A, samples are restricted to employees who occupy section head positions or higher. The number of observations is 352 . For sample B, samples are restricted to employees who occupy department head positions or higher. The number of observations is 150 .

**Significant at the 5 percent level.

*Significant at the 10 percent level. 
nary least squares (OLS) method. It addresses whether promotion to higher positions increases effort (provides incentives) among white-collar employees. Table 11.2 shows the promotion function estimated by the probit method. Since these tables do not take into account the simultaneity property, we discuss them only briefly. The estimated results, nevertheless, reveal several interesting points.

First, the effect of promotion on incentive for effort is statistically insignificant in both samples. Put simply, promoted employees do not feel a strong incentive for effort. This is somewhat surprising, because it is contrary to common beliefs, and because employers expect that promoted employees will be highly motivated.

Second, job tenure or the number of years before reaching section head is positive and significant for promotion to department head, while it is negative and significant or statistically insignificant for promotion to director or deputy director. This distinction suggests that the seniority system works, at least for the promotion to department heads, while it does not work for further promotions.

Third, the number of job sections in which a worker is placed before being promoted to department head is positive and significant for promotion to department head. Thus, capable employees who are promoted to very high positions change their sections more frequently than others. This is consistent with the understanding in Japan that employers try to assign capable white-collar employees to many different job sections in order to provide them with an opportunity to learn a wide range of business activities in the firm. This is called a wide career pattern (see Kioke 1991).

Tables 11.3 through 11.5 present the estimated results taking into consideration the simultaneity property. Tables 11.3 and 11.4 are based on Lee's method, while table 11.5 is based on Heckman's two-step method. Tables 11.3 and 11.4 indicate that the constant term is significantly higher for employees who are promoted to department head (sample A in table 11.3) than for employees who are not promoted (sample A in table 11.4). Thus, promoted employees show higher effort than nonpromoted employees. The results using Heckman's method also support this observation because PROS (the inverse Mills ratio) is positive and significant. It is interesting to note, however, that the estimated result for promotion to director or deputy director is not consistent with the above finding. Perhaps this is because those positions, which are higher than department head, are normally occupied by very capable and ambitious people. Therefore, it is hard to believe that they have different incentive efforts or motivations; everyone in very high positions is well motivated.

Several noteworthy observations regarding the effect of each explanatory variable on the incentive effort follow. The effect of wage satisfaction (SAWD) is negative on incentive effort, while the effect of the future promotion prospective (PROSD) is positive. The former suggests that wages do not have any effect, while the latter implies that when employees feel 


\begin{tabular}{|c|c|c|}
\hline & Coefficient (A) & Coefficient (B) \\
\hline Constant & $\begin{array}{c}-11.337 * * \\
(3.040)\end{array}$ & $\begin{array}{c}-8.079 \\
(5.521)\end{array}$ \\
\hline TENU & $\begin{array}{c}0.394^{* *} \\
(0.188)\end{array}$ & $\begin{array}{c}0.211 \\
(0.354)\end{array}$ \\
\hline PCAR & $\begin{array}{c}-0.079 \\
(0.110)\end{array}$ & $\begin{array}{c}-0.464 * * \\
(0.205)\end{array}$ \\
\hline TENU2 & $\begin{array}{c}0.000 \\
(0.004)\end{array}$ & $\begin{array}{c}-0.002 \\
(0.006)\end{array}$ \\
\hline PCAR2 & $\begin{array}{c}-0.008^{*} \\
(0.004)\end{array}$ & $\begin{array}{c}0.007 \\
(0.005)\end{array}$ \\
\hline IND & $\begin{array}{c}0.117 \\
(0.087)\end{array}$ & $\begin{array}{c}0.119 \\
(0.117)\end{array}$ \\
\hline OUTD & $\begin{array}{c}0.115 \\
(0.070)\end{array}$ & $\begin{array}{l}0.266^{* * *} \\
(0.093)\end{array}$ \\
\hline SHUKO & $\begin{array}{c}0.181 \\
(0.341)\end{array}$ & $\begin{array}{c}0.595 \\
(0.488)\end{array}$ \\
\hline EDUD & $\begin{array}{l}2.346^{* * *} \\
(0.830)\end{array}$ & $\begin{array}{c}0.734 \\
(0.614)\end{array}$ \\
\hline F1D & $\begin{array}{c}-0.892 \\
(0.592)\end{array}$ & - \\
\hline F2D & $\begin{array}{c}0.076 \\
(0.534)\end{array}$ & $\begin{array}{r}-0.214 \\
(0.687)\end{array}$ \\
\hline F3D & $\begin{array}{c}0.344 \\
(1.446)\end{array}$ & $\begin{array}{c}0.030 \\
(0.528)\end{array}$ \\
\hline F4D & $\begin{array}{c}-0.805 \\
(0.574)\end{array}$ & $\begin{array}{r}-0.620 \\
(0.983)\end{array}$ \\
\hline AGE & $\begin{array}{c}0.124 \\
(0.113)\end{array}$ & $\begin{array}{c}0.195 \\
(0.171)\end{array}$ \\
\hline SEXD & $\begin{array}{c}0.047 \\
(0.989)\end{array}$ & $\begin{array}{c}-4.153 \\
(3.060)\end{array}$ \\
\hline PHD & $\begin{array}{c}-0.684^{* *} \\
(0.321)\end{array}$ & $\begin{array}{r}-0.267 \\
(0.501)\end{array}$ \\
\hline STD & $\begin{array}{l}0.846^{* *} \\
(0.243)\end{array}$ & $\begin{array}{c}-0.161 \\
(0.419)\end{array}$ \\
\hline SAWD & $\begin{array}{c}-0.238 \\
(0.272)\end{array}$ & $\begin{array}{c}-0.514 \\
(0.433)\end{array}$ \\
\hline WVARD & $\begin{array}{c}-1.517 * * \\
(0.472)\end{array}$ & $\begin{array}{c}-1.657 * * \\
(0.729)\end{array}$ \\
\hline OPD & $\begin{array}{r}-0.157 \\
(0.238)\end{array}$ & $\begin{array}{r}-0.723 \\
(0.445)\end{array}$ \\
\hline AGRD & $\begin{array}{r}-0.293 \\
(0.342)\end{array}$ & $\begin{array}{c}-0.099 \\
(0.624)\end{array}$ \\
\hline PNOTICED & $\begin{array}{c}0.292 \\
(0.282)\end{array}$ & $\begin{array}{c}0.888 \\
(0.615)\end{array}$ \\
\hline PROSD & $\begin{array}{l}0.560^{* * *} \\
(0.263)\end{array}$ & $\begin{array}{l}1.175^{* *} \\
(0.513)\end{array}$ \\
\hline PVARD & $\begin{array}{c}-0.705^{* *} \\
(0.325)\end{array}$ & $\begin{array}{c}0.778 \\
(0.685)\end{array}$ \\
\hline Log-likelihood & -92.5 & -34.3 \\
\hline
\end{tabular}

Source: Data are from Tachibanaki and Maruyama (1993).

Notes: See table 11.1. 
Model I, Estimated Effort Function (Lee's method), for Promoted Employees

\begin{tabular}{lcc}
\hline & Coefficient (A) & Coefficient (B) \\
\hline \multirow{2}{*}{ Constant } & $2.995^{* *}$ & $2.476^{* *}$ \\
& $(0.220)$ & $(0.917)$ \\
STD & 0.095 & 0.002 \\
& $(0.110)$ & $(0.352)$ \\
SAWD & $-0.507^{* *}$ & -0.317 \\
& $(0.113)$ & $(0.338)$ \\
WVARD & -0.267 & 0.077 \\
OPD & $(0.168)$ & $(0.476)$ \\
& $0.294^{* *}$ & $0.584^{*}$ \\
AGRD & $(0.116)$ & $(0.341)$ \\
& -0.040 & 0.114 \\
PROSD & $(0.178)$ & $(0.496)$ \\
& $0.216^{*}$ & 0.026 \\
PNOTICED & $(0.111)$ & $(0.505)$ \\
& -0.068 & -0.401 \\
PVARD & $(0.145)$ & $(0.644)$ \\
& -0.068 & 0.343 \\
PROS & $(0.150)$ & $(0.804)$ \\
& 0.116 & -0.112 \\
$\bar{R}^{2}$ & $(0.141)$ & $(0.329)$ \\
\end{tabular}

Source: Data are from Tachibanaki and Maruyama (1993).

Notes: See table 11.1.

that there is a good chance of future promotion they show a strong incentive for effort.

Second, the effect of both wage differentials (WVARD) and differentiation in promotion (PVARD) among colleagues employed in the same year is not statistically significant. However, the effect of the propensity to promote (OPD) and of the satisfaction with wage payment (STD) are positive on effort incentive for samples who have been promoted to section head and on those competing for department head. The latter finding suggests that the effect on effort incentive differs according to one's hierarchical position. This is also confirmed by the significantly positive effect of the recognition of promotion possibility among workers (PNOTICED) on effort incentive for samples who have been promoted to section head and for those competing for department head, and by the significantly negative effect of the same variable for samples who have been already promoted to department head.

In summary, the effect of wages is significant only for samples who so far have not been promoted. The effect of satisfaction with wages, however, is significantly negative for all samples. The effect of the recognition of 
Table 11.4

Model I, Estimated Effort Function (Lee's method), for

Nonpromoted Employees

\begin{tabular}{lcc}
\hline & Coefficient (A) & Coefficient (B) \\
\hline Constant & $2.616^{* *}$ & $2.962^{* *}$ \\
& $(0.206)$ & $(0.287)$ \\
STD & 0.157 & 0.075 \\
& $(0.141)$ & $(0.152)$ \\
SAWD & $-0.619^{* *}$ & $-0.690^{* *}$ \\
& $(0.125)$ & $(0.157)$ \\
WVARD & -0.136 & -0.162 \\
OPD & $(0.201)$ & $(0.235)$ \\
& -0.007 & 0.123 \\
AGRD & $(0.128)$ & $(0.159)$ \\
& 0.078 & 0.035 \\
PROSD & $(0.167)$ & $(0.250)$ \\
& $0.361^{* *}$ & $0.275^{*}$ \\
PNOTICED & $(0.125)$ & $(0.163)$ \\
& 0.092 & 0.042 \\
PVARD & $(0.136)$ & $(0.184)$ \\
& 0.027 & -0.114 \\
PROS & $(0.136)$ & $(0.215)$ \\
& $0.281^{* *}$ & 0.068 \\
$\bar{R}^{2}$ & $(0.136)$ & $(0.249)$ \\
& 0.216 & 0.174 \\
\hline
\end{tabular}

Source: Data are from Tachibanaki and Maruyama (1993).

Notes: See appendix for an explanation of variables. Figures in parentheses are standard errors. For sample A, samples are restricted to employees who are not promoted to section head. For sample B, samples are restricted to employees who are not promoted to department head.

**Significant at the 5 percent level.

*Significant at the 10 percent level.

promotion possibility is positive for samples of those in lower positions, while it is negative for samples of those in higher positions. This is consistent with the fact that the number of explanatory variables that are statistically significant on effort incentive decreases when we look at employees who have been promoted to very high positions. This reflects the decreasing role of the incentive mechanism in competition for very high positions. In other words, the incentive mechanism works best for competition within the range of lower positions.

Tables 11.6 through 11.10 show the estimated results for Model II, for both effort incentive functions and wage functions. They are estimated by OLS as well as 2SLS. The distinction between OLS results and 2SLS results gets at whether it is useful to consider the nature of the endogeneity in terms of effort and wages. We find that the effect of wages on effort is statistically significant for the total sample, but not for samples of those 
Model I, Estimated Effort Function (Heckman two-step), for Promoted Employees

\begin{tabular}{lcc}
\hline & Coefficient (A) & Coefficient (B) \\
\hline \multirow{2}{*}{ Constant } & $2.703^{* *}$ & $2.906^{* *}$ \\
STD & $(0.144)$ & $(0.264)$ \\
& 0.126 & 0.087 \\
SAWD & $(0.086)$ & $(0.133)$ \\
& $-0.576^{* *}$ & $-0.632^{* *}$ \\
WVARD & $(0.083)$ & $(0.135)$ \\
& $-0.215^{*}$ & -0.109 \\
OPD & $(0.128)$ & $(0.200)$ \\
& $0.154^{*}$ & 0.217 \\
AGRD & $(0.084)$ & $(0.139)$ \\
& 0.019 & 0.047 \\
PROSD & $(0.122)$ & $(0.218)$ \\
& $0.241^{* *}$ & $0.272^{*}$ \\
PNOTICED & $(0.082)$ & $(0.150)$ \\
& -0.027 & -0.001 \\
PVARD & $(0.098)$ & $(0.174)$ \\
& -0.002 & -0.100 \\
PROS & $(0.100)$ & $(0.201)$ \\
& $0.195^{*}$ & -0.203 \\
$\bar{R}^{2}$ & $(0.106)$ & $(0.219)$ \\
\end{tabular}

Source: Data are from Tachibanaki and Maruyama (1993).

Notes: See appendix for an explanation of variables. Figures in parentheses are standard errors. For sample A, samples are restricted to employees who occupy the position of section head or higher. The number of observations is 352 . For sample B, samples are restricted to employees who occupy the position of department head or higher. The number of observations is 150 .

**Significant at the 5 percent level.

*Significant at the 10 percent level.

who have been promoted to section head and positions higher than section head, such as department head and director. This is true even in the case of the 2SLS method. Therefore, we conclude that when all white-collar employees are considered, wages have an influence on effort and incentive. When only promoted employees are considered, wages have no influence.

The effect of incentive effort on wages is not statistically significant for either OLS or 2SLS results, implying that having a strong effort incentive does not increase the wage payment. Nor do wages decrease when an employee has a strong effort incentive. This implies that wages are not affected by employees' effort level. Still, a strong effort incentive leads to a higher probability of promotion in the lower range of hierarchical positions. Thus, effort is important for promotion in early stages of careers but not important for wages. However, wages are affected by the hierarchical posi- 
Table 11.6

Model II, Estimated Effort Function (OLS)

\begin{tabular}{lccc}
\hline & Coefficient (A) & Coefficient (B) & Coefficient (C) \\
\hline \multirow{2}{*}{ Constant } & $0.814^{* *}$ & $2.116^{*}$ & 2.549 \\
& $(0.414)$ & $(1.094)$ & $(2.204)$ \\
OPD & 0.013 & 0.116 & 0.221 \\
& $(0.051)$ & $(0.086)$ & $(0.143)$ \\
SAWD & $-0.668^{* *}$ & $-0.580^{* *}$ & $-0.635^{* *}$ \\
& $(0.051)$ & $(0.089)$ & $(0.145)$ \\
WVARD & -0.128 & -0.189 & -0.131 \\
& $(0.086)$ & $(0.130)$ & $(0.199)$ \\
PROSD & $0.306^{* *}$ & $0.243^{* *}$ & 0.197 \\
& $(0.054)$ & $(0.082)$ & $(0.137)$ \\
STD & $0.245^{* *}$ & 0.134 & 0.001 \\
& $(0.061)$ & $(0.092)$ & $(0.146)$ \\
PVARD & $0.178^{* *}$ & 0.021 & -0.046 \\
& $(0.055)$ & $(0.104)$ & $(0.173)$ \\
PNOTICED & 0.052 & 0.004 & -0.116 \\
& $(0.055)$ & $(0.098)$ & $(0.202)$ \\
WAGE & $0.266^{* *}$ & 0.103 & 0.063 \\
& $(0.067)$ & $(0.166)$ & $(0.324)$ \\
$\bar{R}^{2}$ & 0.238 & 0.165 & 0.134 \\
\hline
\end{tabular}

Source: Data are from Tachibanaki and Maruyama (1993).

Notes: See appendix for an explanation of variables. Figures in parentheses are standard errors. For sample A, all samples are included. The number of observations is 1,037. For sample B, samples are restricted to employees who occupy the position of section head or higher. The number of observations is 337 . For sample $\mathrm{C}$, samples are restricted to employees who occupy the position of department head or higher. The number of observations is 147.

**Significant at the 5 percent level.

*Significant at the 10 percent level.

tions. In other words, promoted employees receive considerably higher wages than nonpromoted employees. Therefore, effort is important in order to receive higher wages through the indirect effect of promotion, although the direct effect of effort on wages is negligible.

The overall result, in terms of both the number of statistically significant coefficients and the closeness of fit, is excellent for the wage functions. The wage model, which investigates how wages are differentiated by hierarchical position and incentive, is explained fairly well by this specification.

The position variables (POSIT) are statistically significant for all equations, implying that the effect of hierarchical position is always positive regardless of the sample of white-collar workers. In other words, employers pay significantly higher wages to employees who occupy significantly higher positions. Tachibanaki (1996) concluded that hierarchical positions had the strongest effect on wage differentials among employees. The effect of job tenure, shown by both a linear term and its square term, is strongly significant, suggesting that the shape of the wage-tenure profile is convex. 
Model II, Estimated Wage Function (OLS)

\begin{tabular}{lccc}
\hline & Coefficient (A) & Coefficient $(\mathrm{B})$ & Coefficient $(\mathrm{C})$ \\
\hline \multirow{2}{*}{ Constant } & $4.937^{* *}$ & $5.384^{* *}$ & $5.253^{* *}$ \\
POSIT & $(0.083)$ & $(0.128)$ & $(0.219)$ \\
& $0.079^{* *}$ & $0.121^{* *}$ & $0.114^{* *}$ \\
TENU & $(0.015)$ & $(0.018)$ & $(0.033)$ \\
& $0.049^{* *}$ & $0.036^{* *}$ & $0.065^{* *}$ \\
TENU2 & $(0.005)$ & $(0.008)$ & $(0.014)$ \\
& $-0.001^{* *}$ & $-0.001^{* *}$ & $-0.001^{* *}$ \\
PHD & $(0.000)$ & $(0.000)$ & $(0.000)$ \\
& -0.014 & $\mathrm{n} . \mathrm{a}$. & $\mathrm{n} . \mathrm{a}$. \\
AGE & $(0.020)$ & & \\
& $0.015^{* *}$ & $0.009^{* *}$ & 0.010 \\
EDUD & $(0.003)$ & $(0.005)$ & $(0.008)$ \\
& $0.233^{* *}$ & $0.172^{* *}$ & 0.089 \\
SEXD & $(0.030)$ & $(0.034)$ & $(0.055)$ \\
& $0.299^{* *}$ & $0.205^{* *}$ & 0.063 \\
F1D & $(0.035)$ & $(0.054)$ & $(0.088)$ \\
& $-0.082^{* *}$ & -0.043 & $\mathrm{n} . \mathrm{a}$. \\
F2D & $(0.031)$ & $(0.03)$ & -0.022 \\
& -0.013 & $-0.055^{*}$ & $(0.044)$ \\
F3D & $(0.031)$ & $(0.030)$ & $-0.127^{* *}$ \\
& $-0.101^{* *}$ & $-0.139^{* *}$ & $(0.032)$ \\
F4D & $(0.029)$ & $(0.022)$ & $0.088^{* *}$ \\
& 0.005 & $0.113^{* *}$ & $(0.041)$ \\
EFFORT & $(0.029)$ & $(0.026)$ & 0.010 \\
& 0.010 & 0.012 & $0.014)$ \\
$\bar{R}^{2}$ & $(0.009)$ & $(0.010)$ & 0.579 \\
\hline
\end{tabular}

Source: Data are from Tachibanaki and Maruyama (1993).

Notes: See table 11.6. n.a. $=$ not available.

The effect of job tenure on wages also is statistically significant even for employees who occupy higher positions (samples B and C). It was anticipated before we launched this exercise that wages would be unaffected by job tenure for employees who were promoted to higher positions, because the other factors would be more significant than the job-tenure effect for these promoted employees. This turned out to be wrong. However, the estimated $R^{2}$ is considerably lower for sample $\mathrm{C}$, those who occupy very high positions. Other factors, or unobserved factors, such as the employee's contribution to the firm, an assessment of the employee's performance, and so on, may contribute to wage differentials even among employees who occupy very high positions.

The effect of job tenure on wages is a controversial subject in many countries. Some authors believe that unobserved heterogeneity of employees reduces the effect of job tenure on wages, while other authors do not 
Model II, Estimated Effort Function (2SLS)

\begin{tabular}{lccc}
\hline & Coefficient (A) & Coefficient (B) & Coefficient (C) \\
\hline \multirow{2}{*}{ Constant } & -0.126 & $2.974^{* *}$ & $4.744^{*}$ \\
& $(0.567)$ & $(1.277)$ & $(2.768)$ \\
OPD & -0.016 & 0.0113 & 0.214 \\
& $(0.312)$ & $(0.086)$ & $(0.143)$ \\
SAWD & $-0.676^{* *}$ & $-0.559^{* *}$ & $-0.583^{* *}$ \\
& $(0.051)$ & $(0.090)$ & $(0.151)$ \\
WVARD & 0.216 & -0.186 & -0.128 \\
& $(0.086)$ & $(0.131)$ & $(0.199)$ \\
PROSD & $0.284^{* *}$ & $0.250^{* *}$ & 0.223 \\
& $(0.055)$ & $(0.082)$ & $(0.139)$ \\
STD & $0.237^{* *}$ & 0.144 & 0.000 \\
& $(0.061)$ & $(0.092)$ & $(0.145)$ \\
PVARD & $0.127^{*}$ & 0.037 & -0.093 \\
& $(0.059)$ & $(0.104)$ & $(0.202)$ \\
PNOTICED & 0.038 & 0.007 & -0.043 \\
& $(0.055)$ & $(0.098)$ & $(0.173)$ \\
WAGE & $0.419^{* *}$ & -0.028 & -0.262 \\
& $(0.092)$ & $(0.194)$ & $(0.408)$ \\
$\bar{R}^{2}$ & 0.242 & 0.164 & 0.142 \\
\hline
\end{tabular}

Source: Data are from Tachibanaki and Maruyama (1993).

Notes: See table 11.6.

believe it. ${ }^{9}$ Our study proposes that job tenure has a positive effect (with statistical significance) on the wage growth, even after controlling for both job positions and effort incentive, although we do not propose that its effect is smaller than is popularly believed.

Our calculation suggests that the wage increase due to promotion to department head is equivalent to the one due to having four years' job tenure. The comparable figure for promotion to director is two years' job tenure. Our calculation implies that promotion to department head increases wage payment drastically. Since employees know this, they struggle to obtain the position of department head, and it is regarded as a symbol of promotion, power, or prestige by many employees (as Tachibanaki 1998b concludes).

The effect of age on wages is also positive except for employees who are department heads or higher (sample C). As Ohta and Tachibanaki (1997) propose, the effect of age and job tenure on wages should be clearly distinguished, at least in Japan, with respect to its economic interpretation as well as its statistical estimation. The effect of age has some relation to the

9. In the United States, we can raise Abraham and Farber (1987) and Altonji and Shakotko (1987) for the former, and Topel (1991) for the latter. Brunello and Ariga (1995), Genda (1997), and Genda and Yee (1997) are useful for Japan and (South) Korea, respectively. 
Table 11.9

Model II, Estimated Wage Function (2SLS)

\begin{tabular}{lccc}
\hline & Coefficient (A) & Coefficient (B) & Coefficient $(\mathrm{C})$ \\
\hline \multirow{2}{*}{ Constant } & $4.942^{* *}$ & $5.415^{* *}$ & $5.399^{* *}$ \\
POSIT & $(0.091)$ & $(0.143)$ & $(0.245)$ \\
& $0.079^{* *}$ & $0.122^{* *}$ & $0.125^{* *}$ \\
TENU & $(0.015)$ & $(0.018)$ & $(0.035)$ \\
& $0.049^{* *}$ & $0.036^{* *}$ & $0.064^{* *}$ \\
TENU2 & $(0.005)$ & $(0.008)$ & $(0.014)$ \\
& $-0.001^{* *}$ & $-0.001^{* *}$ & $-0.001^{* *}$ \\
PHD & $(0.000)$ & $(0.000)$ & $(0.000)$ \\
& -0.014 & - & - \\
AGE & $(0.020)$ & & \\
& $0.015^{* *}$ & $0.009^{*}$ & 0.011 \\
EDUD & $(0.003)$ & $(0.005)$ & $(0.008)$ \\
& $0.233^{* *}$ & $0.168^{* *}$ & 0.063 \\
SEXD & $(0.030)$ & $(0.035)$ & $(0.060)$ \\
& $0.299^{* *}$ & $0.206^{* *}$ & 0.059 \\
F1D & $(0.035)$ & $(0.054)$ & $(0.087)$ \\
& $-0.083^{* *}$ & -0.044 & - \\
F2D & $(0.032)$ & $(0.031)$ & -0.007 \\
& -0.013 & $-0.053^{*}$ & $(0.046)$ \\
F3D & $(0.032)$ & $(0.030)$ & $-0.115^{* *}$ \\
& $-0.102^{* *}$ & $-0.137^{* *}$ & $(0.033)$ \\
F4D & $(0.029)$ & $(0.022)$ & $0.083^{* *}$ \\
& 0.003 & $0.108^{* *}$ & $(0.041)$ \\
EFFORT & $(0.031)$ & $(0.028)$ & $(0.037)$ \\
& 0.008 & 0.002 & 0.580 \\
$\bar{R}^{2}$ & $(0.022)$ & $(0.024)$ & \\
\hline
\end{tabular}

Source: Data are from Tachibanaki and Maruyama (1993).

Notes: See table 11.6.

life cycle of employees. For example, the older the employee, the more necessary is his or her income. Still, employers do not take into consideration this life-cycle aspect for employees who have been promoted to very high positions.

The effect of education (EDUD) and sex (SEXD) are not statistically significant for department heads and higher (sample C), while they are significant for employees who have not been promoted to very high positions.

We conclude that there are several unobservable factors that affect the determination of wages for employees who have been promoted to department head. Which variables or factors are influential in the determination of wages for employees who occupy very high positions will be a subject of future research.

Tables 11.10 through 11.12 present the estimated results for Model III 


\begin{tabular}{lccc}
\hline & Coefficient (A) & Coefficient (B) & Coefficient (C) \\
\hline \multirow{2}{*}{ Constant } & 1.715 & $5.276^{* *}$ & 4.119 \\
& $(1.116)$ & $(2.163)$ & $(3.233)$ \\
OPD & 0.026 & 0.116 & 0.213 \\
& $(0.051)$ & $(0.086)$ & $(0.143)$ \\
SAWD & $-0.671^{* *}$ & $-0.519^{* *}$ & $-0.594^{* *}$ \\
& $(0.051)$ & $(0.095)$ & $(0.154)$ \\
WVARD & 0.114 & -0.209 & -0.120 \\
& $(0.086)$ & $(0.132)$ & $(0.200)$ \\
PROSD & $0.239^{* *}$ & $0.213^{* *}$ & $0.269^{*}$ \\
& $(0.058)$ & $(0.087)$ & $(0.161)$ \\
STD & $0.198^{* *}$ & 0.109 & 0.006 \\
& $(0.064)$ & $(0.096)$ & $(0.146)$ \\
PVARD & 0.084 & 0.032 & -0.069 \\
& $(0.061)$ & $(0.105)$ & $(0.207)$ \\
PNOTICED & 0.029 & -0.027 & -0.024 \\
& $(0.055)$ & $(0.102)$ & $(0.177)$ \\
WAGE & 0.119 & -0.413 & -0.118 \\
& $(0.181)$ & $(0.351)$ & $(0.542)$ \\
POSIT & $0.191^{* *}$ & 0.203 & -0.194 \\
& $(0.091)$ & $(0.156)$ & $(0.371)$ \\
$\bar{R}^{2}$ & 0.246 & 0.166 & 0.138 \\
\hline
\end{tabular}

Source: Data are from Tachibanaki and Maruyama (1993).

Notes: See table 11.6.

Table 11.11 Model III, Estimated Position Function (2SLS)

\begin{tabular}{cccc}
\hline & Coefficient (A) & Coefficient (B) & Coefficient (C) \\
\hline \multirow{2}{*}{ Constant } & $-2.148^{* *}$ & $-2.062^{* *}$ & 0.204 \\
& $(0.112)$ & $(0.263)$ & $(0.416)$ \\
TENU & $0.136^{* *}$ & $0.145^{* *}$ & $0.067^{* *}$ \\
& $(0.008)$ & $(0.0172)$ & $(0.029)$ \\
TENU2 & $-0.002^{* *}$ & $-0.001^{* *}$ & -0.001 \\
& $(0.000)$ & $(0.000)$ & $(0.001)$ \\
EDUD & $0.843^{* *}$ & $0.956^{* *}$ & $0.600^{* *}$ \\
\multirow{2}{*}{ EFFORT } & $(0.050)$ & $(0.072)$ & $(0.099)$ \\
& $0.295^{* *}$ & $0.311^{* *}$ & $0.123^{*}$ \\
$\bar{R}^{2}$ & $(0.043)$ & $(0.062)$ & $(0.070)$ \\
\hline
\end{tabular}

Source: Data are from Tachibanaki and Maruyama (1993).

Notes: See table 11.6. 
Table 11.12

Model III, Estimated Wage Function (2SLS)

\begin{tabular}{lccc}
\hline & Coefficient (A) & Coefficient (B) & Coefficient $(\mathrm{C})$ \\
\hline \multirow{2}{*}{ Constant } & $5.290^{* *}$ & $5.672^{* *}$ & $5.140^{* *}$ \\
& $(0.159)$ & $(0.158)$ & $(0.212)$ \\
TENU & $0.038^{* *}$ & $0.020^{* *}$ & $0.054^{* *}$ \\
& $(0.007)$ & $(0.010)$ & $(0.014)$ \\
TENU2 & $-0.001^{* *}$ & $-0.000^{*}$ & $-0.001^{* *}$ \\
& $(0.000)$ & $(0.000)$ & $(0.000)$ \\
PHD & -0.018 & 0.010 & 0.014 \\
& $(0.020)$ & $(0.020)$ & $(0.030)$ \\
AGE & $0.008^{* *}$ & 0.003 & 0.003 \\
& $(0.005)$ & $(0.006)$ & $(0.008)$ \\
EDUD & $0.143^{* *}$ & 0.060 & -0.054 \\
& $(0.048)$ & $(0.053)$ & $(0.065)$ \\
SEXD & $0.291^{* *}$ & $0.228^{* *}$ & $0.177^{*}$ \\
F1D & $(0.035)$ & $(0.056)$ & $(0.090)$ \\
& -0.032 & 0.008 & 0.089 \\
F2D & $(0.038)$ & $(0.034)$ & $(0.056)$ \\
& 0.051 & -0.013 & 0.023 \\
F3D & $(0.041)$ & $(0.024)$ & $(0.046)$ \\
& $-0.108^{* *}$ & $0.153^{* *}$ & $-0.084^{* *}$ \\
F4D & $(0.029)$ & $(0.032)$ & $(0.036)$ \\
POSIT & 0.043 & $0.153^{* *}$ & $0.139^{* *}$ \\
& $(0.033)$ & $(0.032)$ & $(0.044)$ \\
$R^{2}$ & $0.214^{* *}$ & $0.267^{* *}$ & $0.390^{* *}$ \\
\hline
\end{tabular}

Source: Data are from Tachibanaki and Maruyama (1993).

Notes: See table 11.6.

based on the 2SLS method. There are three endogenous variables, EFFORT, WAGE, and PROMOTION, and many exogenous variables. Since Model III is essentially a combined version of Model I and Model II, we do not discuss it in detail here. It simply intends to find the casual relationship among hierarchical position, effort incentive, and wages. Another important feature of tables 11.10 through 11.12 is that the model is estimated for separate samples - total sample, employees who have been promoted to section head and higher, and employees who have been promoted to department head and higher-as in the previous tables.

In tables 11.10 through 11.12, the estimated results are best for "all samples," and inferior when samples are restricted to employees who occupy higher positions. This was also true in Models I and II and implies that while the theoretical framework adopted in this study is supported for all samples, it is not supported for samples of those who occupy very high positions. It is likely that there are several unobservable variables for these 
samples, such as contribution to the firm, the firm's performance in profits or sales, and so on.

Further, the principal causality proceeds in the following way: position $\rightarrow$ effort incentive $\rightarrow$ wages. Position and effort affect each other, but wages have no effect on them except for samples of those who have not been promoted yet.

\subsection{Who Is Promoted?}

The previous sections presented several models and estimated their parameters empirically. However, the results did not show who is promoted, and on what criteria. This section is concerned with that question, although the method of investigation is descriptive.

We use the same data source, including questions such as "What are the reasons or criteria for the determination of promotion to department head and director?" The questionnaire is based on self-assessment of whitecollar employees regarding the issue of promotion.

Table 11.13 shows the most important, second most important, and third most important criteria for promotion to department head and director, respectively. For promotion to department head, the most important criterion is the performance evaluation of an individual employee. The next most important is age and job tenure, followed by education. As for the second set of important criteria, age and job tenure are the highest, followed by performance evaluation and a manager's "pull." For the third set, managerial pull and personal character were about the same in importance.

For promotion to director, the most important criteria are the performance evaluation of an individual employee and managerial pull. They are virtually equal. Performance evaluation is less important for promotion to director than for promotion to department head. Of secondary importance are managerial pull and performance evaluation, which rank almost the same. Personal character is also fairly important. For the third set, personal character is the highest-much higher than the other criteria in the third set.

The discussion of promotion in Japanese firms may be summarized as follows: Before being promoted to department head, it is crucial to have excellent performance in business and to reveal one's capability and productivity to colleagues and managers. Since the effects of age and job tenure are quite important, too, even an extremely capable employee who shows excellent performance cannot expect to be promoted extremely rapidly. At the same time, even a less capable employee, or one with inferior performance in business, can be promoted up to a certain limited level, although more slowly. The record of an employee's performance during his or her career is documented, however, and it is certainly used as information for future promotion possibility. 


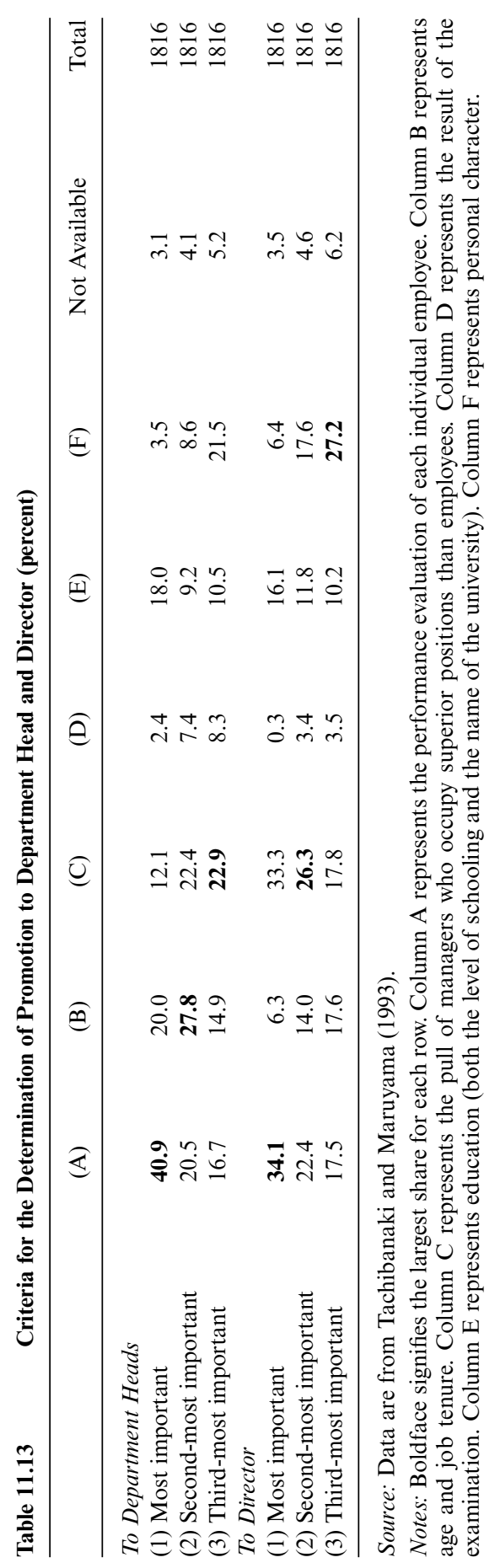


After being promoted to department head, the information on past and current performance in business determines the possibility of promotion to deputy director and director. At the same time, pull by superior managers becomes important at this stage. "Pull" is a mysterious element in the following senses: First, it may be equivalent to favoritism, as (for example) among relatives, graduates of the same university, or those with the same personal likes and dislikes. Second, an extremely powerful and influential manager is likely first to pick and then to recommend a capable subordinate for a higher position. Third, a much less capable employee, one with inferior performance, cannot be a candidate for the influence of managerial pull because the use of this influence would be judged unfair for such a person. Thus, pull may be called "luck" in some sense. Finally, good personal character matters to a certain extent. ${ }^{10}$

\subsection{Concluding Remarks}

This study investigated the relationship among promotion, effort incentive, and wages. Individual observations on white-collar workers in several large Japanese firms were used to investigate this issue. We obtained the following findings.

First, the employee's position on the hierarchical ladder is crucial in understanding the relationship among promotion, effort incentive, and wages. The effect of wages on effort is important for employees early in their careers or before being promoted. The higher the wage payment, the higher the effort from these employees. However, the crucial variable that increases effort for employees in mid-career is promotion prospective as measured by, for example, better performance in business. In the samples of workers promoted to department-head level, there is no incentive mechanism that works. In other words, neither prospective promotion nor wages affects the effort of employees who occupy very high positions. Unobservable factors, possibly including managerial pull (or luck) are important for these employees in terms of their promotion incentive.

Next, effort can be increased only for employees who are early in their careers, or are lower on the hierarchical ladder. There are several methods to increase the incentive for these employees: showing an explicit or implicit sign of the prospect of early promotion; providing frequent internal transfers among different sections; or using information on the employee's capability and sharing it among other employees who are in very early career stages. One important reason why the effort incentive mechanism works only for employees in early careers, or lower on the hierarchical ladder, is that employees who have been promoted quickly to higher posi-

10. Tachibanaki (1998a) investigated promotions to the highest positions, namely to top executive (board member), and presented several useful observations. 
tions have already shown their excellent performance and capability, and thus they are highly motivated in any case.

Our estimated wage functions worked well even for white-collar employees. We confirmed the role of hierarchical positions in wage differentials in this study. In particular, we found that the level of wages jumps considerably when an employee is promoted to department head.

We also found age and job tenure to be effective for the determination of both the promotion possibility and wages. For the former, age and job tenure were secondarily important to employees early in their careers, following performance evaluation. For wages, the effect of job tenure was prevalent even after controlling for the simultaneous presence of hierarchical position and job tenure.

Finally, what determines promotion, or how to select promoted employees, differs according to the position. In other words, the decision-making variables are different for promotion to department head versus promotion to director. Very simply speaking, performance evaluation of an individual employee and job tenure matter for department head positions, whereas performance evaluation and managerial pull perhaps matter for the position of director.

What are the implications for human resource management in view of the recent aging trend in the Japanese population and the slower growth rate of firms in Japan? It is essential for firms to reduce the cost of labor and, at the same time, to raise productivity of employees by increasing their incentives. Competition among employees, in particular younger and not-yet-promoted employees, is desirable to achieve such a goal. Competition in terms of merit, evaluated by the contribution and performance of each individual employee, is likely to distinguish between capable employees and less capable ones in their early careers. Quicker promotions for more capable employees and wider wage differentials among employees are unavoidable.

\section{Appendix}

\section{List of Variables}

EFFORT: Work effort compared with job requirements

4: contribution to the firm higher than required

3: contribution to the firm somewhat higher than required

2: contribution to the firm almost equivalent to requirements

1: needs somewhat higher effort

0 : needs higher effort 
PROM (or PROD): A dummy variable for promotion

1: promoted

0 : not promoted

WAGE: Natural log of annual wage

OPD: A dummy variable for propensity to promote

1 : strong propensity

2: no propensity

SAWD: Own evaluation of wage compared with contribution to the firm

1: wage is higher than contribution

0 : otherwise

WVARD: Wage differentials among colleagues who were employed in the same year

1: wide differential

0 : small or no differential

PROSD: A dummy variable for prospect of promotion

1: expecting to be promoted to director

0 : otherwise

STD: Satisfaction with wage payment

1: satisfied

0 : otherwise

PVARD: A dummy variable for whether promotion is differentiated among colleagues who were employed in the same year

1 : yes

$0:$ no

AGRD: Propensity to compete with other people

$1:$ yes

0 : no

PNOTICED: A dummy variable for whether promotion possibility is easily recognized among workers

1 : yes

$0:$ no

TENU: Job tenure (TENU2 is its squared form)

PCAR: Years toward section head (PCAR2 is its squared form) for samples of section heads and higher positions. Years towards department head for samples of department heads and higher positions.

AGE: Age

SEXD: A dummy variable for sex

1: male

0 : female 
EDUD: A dummy variable for university education

1: university

0 : otherwise

PHD: A dummy variable for specialty in university education

1: law and economics

0 : otherwise

IND: The number of changes in job section before promotion to section head

OUTD: The number of changes in job section before promotion to department head

SHUKO: A dummy variable for temporary work in the subsidiary firm

1: yes

2: otherwise

BUKAD: A dummy variable for whether an individual department head has subordinates

1: yes

2: no

F1D-F4D: Dummy variables for particular firms

POSIT: Variables for positions

3: higher than deputy director

2: division head

1: section head

0 : otherwise

\section{Model Specification}

\section{Model I}

EFFORT $=X+$ PROM

PROM $=Z+$ EFFORT

$\mathrm{X}, \mathrm{Z}$ : exogenous variables;

\section{Model II}

EFFORT $=\mathrm{X}+$ WAGE

$\mathrm{WAGE}=\mathrm{Y}+$ EFFORT

$\mathrm{X}, \mathrm{Y}$ : exogenous variables;

\section{Model III}

EFFORT $=\mathrm{X}+$ PROM + WAGE

WAGE $=\mathrm{Y}+$ PROM

$\mathbf{P R O M}=\mathrm{Z}+$ EFFORT

$\mathrm{X}, \mathrm{Y}, \mathrm{Z}$ : exogenous variables; 
where EFFORT may be interpreted as incentive, and PROM signifies promotion possibility where it is defined discretely in some cases. Boldface implies the possibility of such a discrete nature. WAGE is the annual wage payment.

\section{References}

Abraham, K. G., and H. S. Farber. 1987. Job duration, seniority, and earnings. American Economic Review 77:278-97.

Altonji, J. S., and R. A. Shakotko. 1987. Do earnings rise with job seniority? Review of Economic Studies 69:437-59.

Ariga, K., Y. Ohkusa, and G. Brunello. 1997. Fast track: Is it in the genes? The promotion policy of a large Japanese firm. Kyoto Institute of Economic Research. Discussion Paper no. 452.

Baker, G., R. Gibbs, and B. Holmstrom. 1994a. The internal economics of the firm: Evidence from personal data. Quarterly Journal of Economics 109:881-919. 1994b. The wage policy of a firm. Quarterly Journal of Economics 109: 492-525.

Baker, G., R. Gibbs, and K. J. Murphy. 1994. Subjective performance measures in optimal incentive contracts. Quarterly Journal of Economics 109:1125-56.

Becker, G. 1962. Human capital. New York, NY: Columbia University Press.

Bruderl, J., A. Diekman, and P. Preisendörfer. 1991. Patterns of intraorganizational mobility: Tournament models, path dependency, and early promotion effects. Social Science Research 20:197-216.

Brunello, G., and K. Ariga. 1995. Is the tenure-earning curve really steeper in Japan? A re-examination based on U.K.-Japan comparison. In The structure of the Japanese economy, ed. M. Okabe, 109-34. London: Macmillan.

Carmichael, L. 1983. Firm-specific human capital and promotion ladders. Bell Journal of Economics 14:251-58.

Genda, Y. 1997. Japan. In Wage differentials: An international comparison, ed. T. Tachibanaki, chap. 2. London: Macmillan.

Genda, Y., and S. Y. Yee. 1997. Wage determination and labour turnover in Korea. In Wage differentials: An international comparison, ed. T. Tachibanaki, chap. 3. London: Macmillan.

Gibbons, R. 1997. Incentives and careers in organizations. In Advances in economic theory and econometrics, ed. D. Kreps and K. Wallis, 1-37. New York: Cambridge University Press.

Harris, M., and B. Holmstrom. 1982. A theory of wage dynamics. Review of Economic Studies 49:315-33.

Hashimoto, M. 1981. Firm-specific human capital as a shared investment. American Economic Review 71:475-81.

Holmstrom, B. 1979. Moral hazard in teams. Bell Journal of Economics 13:324-40.

Ishikawa, T. 1992. Distribution in income and wealth (in Japanese). Tokyo: Iwanami-shoten.

Ito, H., and H. Teruyama. 1998. Effort incentive: Evidence from Japanese data. In Who runs Japanese business? ed. T. Tachibanaki, chap. 6. London: Elgar.

Koike, K. 1991. Economics of jobs (in Japanese). Tokyo: Toyokeizai-shimposha.

Lazear, E. 1979. Why is there mandatory retirement? Journal of Political Economy $87: 1261-84$. 
97:561-80.

Matsushige, T. 1998. White-collar careers in a large electronics company. In Who runs Japanese business? ed. T. Tachibanaki, chap. 7. London: Elgar.

Mincer, J., and Y. Higuchi. 1988. Wage structures and labour turnover in the United States and Japan. Journal of the Japanese and International Economies 2:97-133.

Mitani, N. 1998. Work incentive of white-collars in wages and promotion. In Who runs Japanese business? ed. T. Tachibanaki, chap. 5. London: Elgar.

Murphy, K. J. 1986. Incentives, learning and compensation: A theoretical and empirical investigation of managerial labor contracts. Rand Journal of Economics 17:59-76.

Ohashi, I. 1998. The name of the university matters? In Who runs Japanese business? ed. T. Tachibanaki, chap. 8. London: Elgar.

Ohashi, I., and T. Matsushige. 1994. The growth of the firm and promotions in the Japanese seniority system. In Labour market and economic performance: Europe, Japan and the U.S.A. ed. T. Tachibanaki, 131-54. London: Macmillan.

Ohta, S., and T. Tachibanaki. 1997. Job tenure versus age: Their effects on wages, and the implication of consumption for wages. In Internal labour market incentives and employment, ed. I. Ohashi and T. Tachibanaki, chap. 3. London: Macmillan.

Ohtake, F. 1995. The determinants of promotion: The effects of length of tenure and performance evaluation (in Japanese). Keizai Kenkyu 46:241-48.

Prendergast, C. 1999. Provision of incentives in firms. Journal of Economic Literature 37:7-63.

Prendergast, C., and R. H. Topel. 1996. Favoritism in organizations. Journal of Political Economy 104:958-78.

Tachibanaki, T. 1982. Further results on Japanese wage differentials: Nenko wages, hierarchical positions, bonuses and working hours. International Economic Review 33:447-61.

. 1987. The determination of the promotion process in organizations and of earnings differentials. Journal of Economic Behaviour and Organizations 8: 603-16.

. 1996. Wage determination and distribution in Japan. Oxford, England: Clarendon. millan.

ed. 1997. Wage differentials: An international comparison. London: Mac-

1998a. Roads towards top executive positions (board members) and their management goals. In Who runs Japanese business? ed. T. Tachibanaki, chap. 2. London: Elgar.

- ed. 1998b. Who runs Japanese business? London: Elgar.

Tachibanaki, T., and T. Maruyama. 1993. Survey of white collar employees. Tokyo: Research Institute for Advancement of Living Standards (RIALS).

Tomita, Y. 1992. System of promotion: An influence of assessment and job tenure. In Assessment, promotion and wage determination (in Japanese), ed. T. Tachibanaki, 49-65. Tokyo: Yuhikaku.

Topel, R. 1991. Specific capital, mobility and earnings: Earnings rise with job seniority. Journal of Political Economy 99:145-76. 
